\title{
IN-SEASON ASSESSMENT OF WHEAT CROP HEALTH USING VEGETATION INDICES BASED ON GROUND MEASURED HYPER SPECTRAL DATA
}

\author{
${ }^{1}$ Khalid Ali Al-Gaadi, ${ }^{2}$ Virupakshagouda Patil, ${ }^{2}$ ElKamil Tola, \\ ${ }^{2}$ Rangaswamy Madugundu and ${ }^{2}$ Samy Marey \\ ${ }^{1}$ Department of Agricultural Engineering, Precision Agriculture Research Chair, \\ College of Food and Agriculture Sciences, King Saud University, Riyadh, Saudi Arabia \\ ${ }^{2}$ Precision Agriculture Research Chair, King Saud University, Riyadh, Saudi Arabia
}

Received 2013-12-09; Revised 2013-12-16; Accepted 2014-01-07

\begin{abstract}
An experiment on a 50 ha center pivot field was conducted to determine the Vegetation Indices (VI's) that were helpful in assessing the in-season performance of wheat crop treated with graded levels of irrigation water and fertilizers. The irrigation levels were at 100, 90, 80 and 70\% Evapotranspiration (ETc); however, the fertilizer levels of $\mathrm{N}: \mathrm{P}: \mathrm{K} \mathrm{kg}^{-1}$ ha included 300:150:200 (low); 400:250:300 (medium) and 500:300:300 (High). The crop was sown on January 1st and harvested on May 9th, 2012. Temporal data on biophysical parameters and reflectance of the crop in hyper spectral bands (350-2500 nm) were collected at booting and ripening growth stages (February 17th and April 5th, 2012). Results of the study revealed that many of the tested spectral indices showed significant response to irrigation levels. Out of those, only two spectral indices (Plant Senescence Reflectance Index 'PSRI' and Photochemical Reflectance Index 'PRI') also exhibited significant response to fertilizer levels. The Middle Infrared-Based Vegetation Index (MIVI) showed a significant response to the irrigation levels for both sampling dates. Among the tested spectral indices, Normalized Difference Infrared Index (NDII) and Normalized Difference Nitrogen Index (NDNI) exhibited the highest correlation to crop Leaf Area Index (LAI). Five indices showed the most response to wheat grain yield. These indices included Near Infrared band (NIR), Water Band Index (WBI), Normalized Water Index-1 (NWI-1), Normalized Water Index-3 (NWI-3) and Normalized Water Index-4 (NWI-4).
\end{abstract}

Keywords: Remote Sensing, Spectral Reflectance, Vegetation Indices, Wheat

\section{INTRODUCTION}

The use of remote sensing applications for crop growth monitoring is becoming an essential part of today's agriculture as it enhances the efficient management of agricultural resources. Because of the strong impact of deficiencies in the essential nutrients on crop growth and yield, assessment of biophysical parameters is necessary for monitoring crop performance and improving crop yield by site specific application of crop chemicals (Haboudane et al., 2007). According to the fact that crop phonological stages and growth period vary in different areas and cropping seasons and to the fact that crop phenology is affected by both weather variations and regional planting habits, determination of the important crop phonological stages is a key factor for modeling crop performance as well as improving the accuracy of crop type classification and yield estimation (Meng et al., 2009). The key factor for precision crop growth monitoring is the selection of the efficient devices and methods for the accurate measurements of crop growth parameters.

Corresponding Author: Khalid Ali Al-Gaadi, Department of Agricultural Engineering, Precision Agriculture Research Chair, College of Food and Agriculture Sciences, King Saud University, Riyadh, Saudi Arabia 
Crop spectral reflectance measurements are being used efficiently for crop growth monitoring as they reflect wide range of biochemical and physiological measures. Thus, remote sensing applications based on the measurement and interpretation of the spectral reflectance of agricultural crops are considered as the most important tools for the assessment of crop growth and yield performance (Aparicio et al., 2000).

Hyper-spectral data provides significant information for discriminating land cover types, identifying small differences in green vegetation cover and crop moisture, in addition to the detection of plant stress. However, large volume of data poses a challenge for data processing and extracting crucial information. Therefore, the analysis of hyper-spectral data, to clearly interpret plant response to management practices, is crucial (Stellacci et al., 2012) Spectral vegetation indices, determined mathematically at various spectral bands, are considered as semi-analytical measures of vegetation activity and appropriate for the assessment of spatial variability in agricultural fields (Vina et al., 2011). These vegetation indices will enhance the interpretation process of the crop spectral reflectance measured at different growth stages and hence will help in understanding the response of agricultural crops to management practices. Therefore, remote sensing based on various vegetation indices (VI) is expected to provide important information that will help in the efficient assessment of within-field spatial variability of various agronomic parameters (Hatfield and Prueger, 2010).

Leaf Area Index (LAI), defined as the ratio of total upper leaf surface of vegetation divided by the surface area of the land on which the vegetation grows, is characterized as one of the most essential structural parameter of crop canopy (Lan et al., 2009). Also, LAI is considered as one of the most important biophysical parameters for the assessment of crop performance (vegetation health, biomass and photosynthesis) and for estimating crop yield. Monitoring the crop LAI during the cropping season will help in understanding the spatial variability in crop productivity. On the other hand, LAI can serve as indicator of stress in vegetation, crop growth performance and energy exchange (Duchemin et al., 2006; Zhang et al., 2012) According to problems associated with the in-situ measurement of Leaf Area Index (LAI), as it is considered to be timeconsuming, expensive and sometimes unfeasible, developments in the field of hyper spectral remote sensing provide new ways for monitoring plant growth through the estimation of vegetation biophysical properties such as LAI (Darvishzadeh et al., 2006).

The main goal of the study was to provide an efficient means of performance evaluation of the wheat crop under different treatments. This was to be achieved through determining the Vegetation Indices (VI's) that could be used in assessing the in-season performance of wheat crop cultivated under different levels of irrigation water and fertilizer rates.

\section{MATERIALS AND METHODS}

\subsection{Study Area}

The study was conducted on a 50 ha sandy loam soil field in Todhia farm located in the Eastern Province of Saudi Arabia within the latitudes of $24^{\circ}$ $10^{\prime} 22.7^{\prime \prime}$ and $24^{\circ} 12^{\prime} 37.2^{\prime \prime} \mathrm{N}$ and longitudes of $47^{\circ}$ 56' 14.6" and $48^{\circ} 05$ '08.56" E Fig. 1. The field was under center pivot irrigation system and has been under continuous wheat (Triticum aestivum L., cv. Yecora Rojo) cultivation.

\subsection{Experimental Layout}

The experiment was conducted on the study field which was cultivated with wheat crop (Triticum aestivum L., cv. Yecora Rojo) sown at $250 \mathrm{~kg}^{-1}$ on January 1th, 2012. Experimental treatments were laid out in split plot design with four irrigation levels as the main treatments and three fertilizer levels as the subtreatments Fig. 2. The main treatments were I1 (irrigation at $100 \%$ ETc), I2 (Irrigation at $90 \%$ ETc), I3 (Irrigation at $80 \% \mathrm{ETc}$ ) and I4 (Irrigation at $70 \% \mathrm{ETc}$ ). The sub-treatments, however, includedF1 (300:200:200), F2 (400:250:250) and F3 (500:300:300) (N: $\mathrm{P}_{2} \mathrm{O}_{5}: \mathrm{K}_{2} \mathrm{O} \mathrm{kg}{ }^{-1}$ ha). Three samples were taken from each treatment to compose the data set for this study.

\subsection{Spectral Reflectance Measurements}

Wheat crop samples were collected on two different dates (February 17th and April 5th, 2012) that coincided with booting and early ripening growth stages. The crop spectral reflectance of the collected samples was measured in the Laboratory by a Spectroradiometer (Model-Field Spec 3 of ASD Inc. Colorado, USA) using the contact probe. The spectral reflectance was measured for wavelengths between 350 and $2500 \mathrm{~nm}$, with an increment of $1 \mathrm{~nm}$.

\subsection{Calculation of Spectral Vegetation Indices}

Vegetation Indices (VI's) which represented combinations of surface reflectance at two or more wavelengths designed to highlight a specific vegetation property (EXELES, 2009) were calculated using the measured wheat crop spectral reflectance values. The 22 vegetation indices investigated in this study and the formulas used to calculate them are presented in Table 1. 


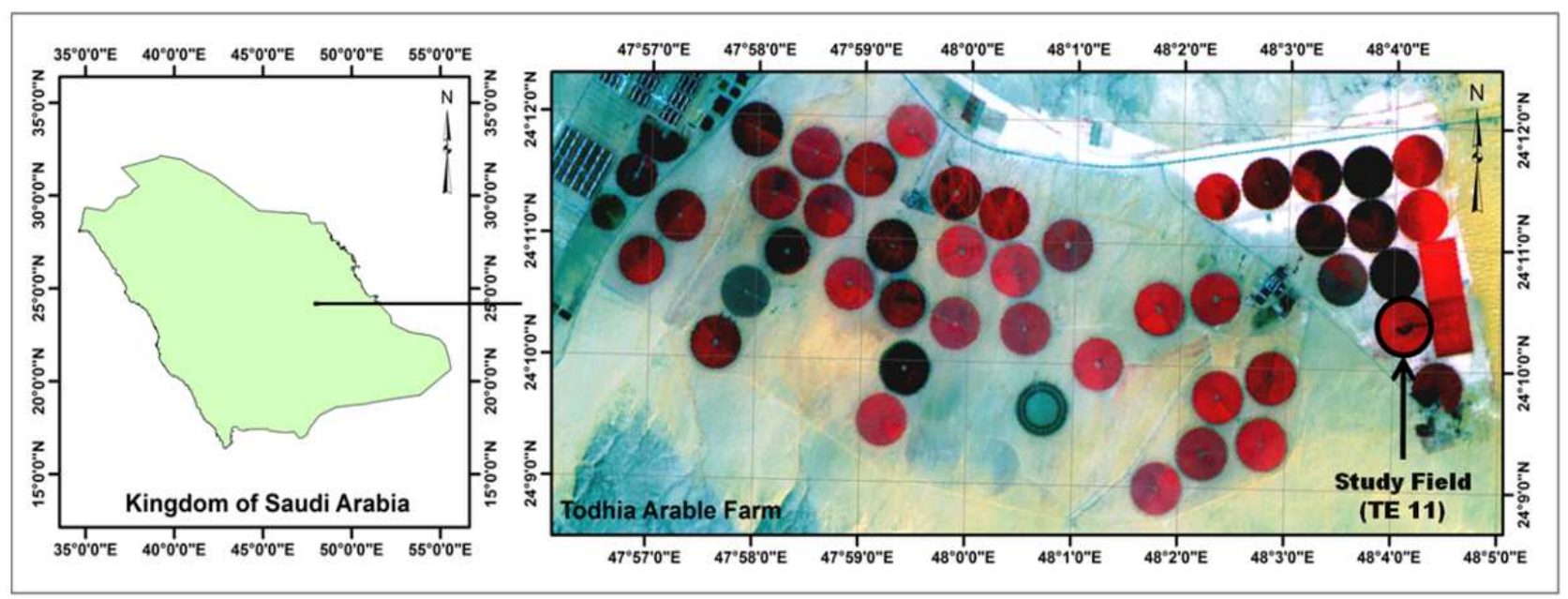

Fig. 1. Location of the study site

Table 1. The formulae for calculation of the Vegetation Indices

\begin{tabular}{|c|c|c|}
\hline $\begin{array}{l}\text { Spectral } \\
\text { Index }\end{array}$ & Description & Formula \\
\hline MIVI & Middle Infrared-Based Vegetation Index & $\begin{array}{l}\text { (MIR1-RED)/(MIR1 + RED) } \\
\text { Where MIR1 (TM5): } 1550 \text { to } 1750 \mathrm{~nm}\end{array}$ \\
\hline $\mathrm{NDVI}_{705}$ & $\begin{array}{l}\text { Red Edge Normalized Difference } \\
\text { Vegetation Index }\end{array}$ & $\left(\rho_{750}-\rho_{705}\right) /\left(\rho_{750}+\rho_{705}\right)^{*}$ \\
\hline $\mathrm{mNDVI}_{705}$ & $\begin{array}{l}\text { Modified Red Edge Normalized } \\
\text { Difference Vegetation Index }\end{array}$ & $\left(\rho_{750}-\rho_{705}\right) /\left(\rho_{750}+\rho_{705}-2 \rho_{445}\right)$ \\
\hline SIPI & Structure Independent Vegetation Index & $\left(\rho_{800}-\rho_{445}\right) /\left(\rho_{800}+\rho_{445}\right)$ \\
\hline PSRI & Plant Senescence Reflectance Index & $\left(\rho_{680}-\rho_{500}\right) /\left(\rho_{750}\right)$ \\
\hline NDWI & Normalized Water Difference Index & $\left(\rho_{857}-\rho_{1241}\right) /\left(\rho_{857}+\rho_{1241}\right)$ \\
\hline MSI & Moisture Stress Index & $\left(\rho_{1599}\right) /\left(\rho_{819}\right)$ \\
\hline NDVI & Normalized Difference Vegetation Index & $\left(\rho_{\mathrm{NIR}}-\rho_{\mathrm{RED}}\right) /\left(\rho_{\mathrm{NIR}}+\rho_{\mathrm{RED}}\right)$ \\
\hline PRI & Photochemical Reflectance Index & $\left(\rho_{531}-\rho_{570}\right) /\left(\rho_{531}+\rho_{570}\right)$ \\
\hline WBI & Water Band Index & $\left(\rho_{900}\right) /\left(\rho_{970}\right)$ \\
\hline $\mathrm{mSR}_{705}$ & Modified Red Edge Simple Ratio & $\left(\rho_{750}-\rho_{445}\right)\left(\rho_{705}-\rho_{445}\right)$ \\
\hline VOG3 & Vogelmann Red Edge Index 3 & $\left(\rho_{734}-\rho_{747}\right) /\left(\rho_{715}-\rho_{720}\right)$ \\
\hline NDNI & Normalized Difference Nitrogen Index & $\begin{array}{l}{\left[\log \left(1 / \rho_{1510}\right)-\log \left(1 / \rho_{1680}\right)\right] /\left[\log \left(1 / \rho_{1510}\right)\right.} \\
\left.+\log \left(1 / \rho_{1680}\right)\right]\end{array}$ \\
\hline NDLI & Normalized Difference Lignin Index & $\begin{array}{l}{\left[\log \left(1 / \rho_{1754}\right)-\log \left(1 / \rho_{1680}\right)\right] /\left[\log \left(1 / \rho_{1754}\right)\right.} \\
\left.+\log \left(1 / \rho_{1680}\right)\right]\end{array}$ \\
\hline NDII & Normalized Difference Infrared Index & $\left(\rho_{819}-\rho_{1649}\right) /\left(\rho_{819}-\rho_{1649}\right)$ \\
\hline NWI-1 & Normalized Water Index-1 & $\left(\mathrm{R}_{970}-\mathrm{R}_{900}\right) /\left(\mathrm{R}_{970}+\mathrm{R}_{900}\right)^{*}$ \\
\hline NWI-2 & Normalized Water Index-2 & $\left(\mathrm{R}_{970}-\mathrm{R}_{850}\right) /\left(\mathrm{R}_{970}+\mathrm{R}_{850}\right)$ \\
\hline NWI-3 & Normalized Water Index-3 & $\left(\mathrm{R}_{970}-\mathrm{R}_{880}\right) /\left(\mathrm{R}_{970}+\mathrm{R}_{880}\right)$ \\
\hline NWI-4 & Normalized Water Index-4 & $\left(\mathrm{R}_{970}-\mathrm{R}_{920}\right) /\left(\mathrm{R}_{970}+\mathrm{R}_{920}\right)$ \\
\hline REIP & Red Edge Inflection Point & $\begin{array}{l}700+40\left\{\left[\left(\rho_{667}+\rho_{782}\right) / 2\right]-\rho_{702}\right\} \\
/\left(\rho_{738}-\rho_{702}\right)\end{array}$ \\
\hline
\end{tabular}

References

EXELES, 2013

Gutierrez et al. (2010)

Herrmann et al. (2010) 


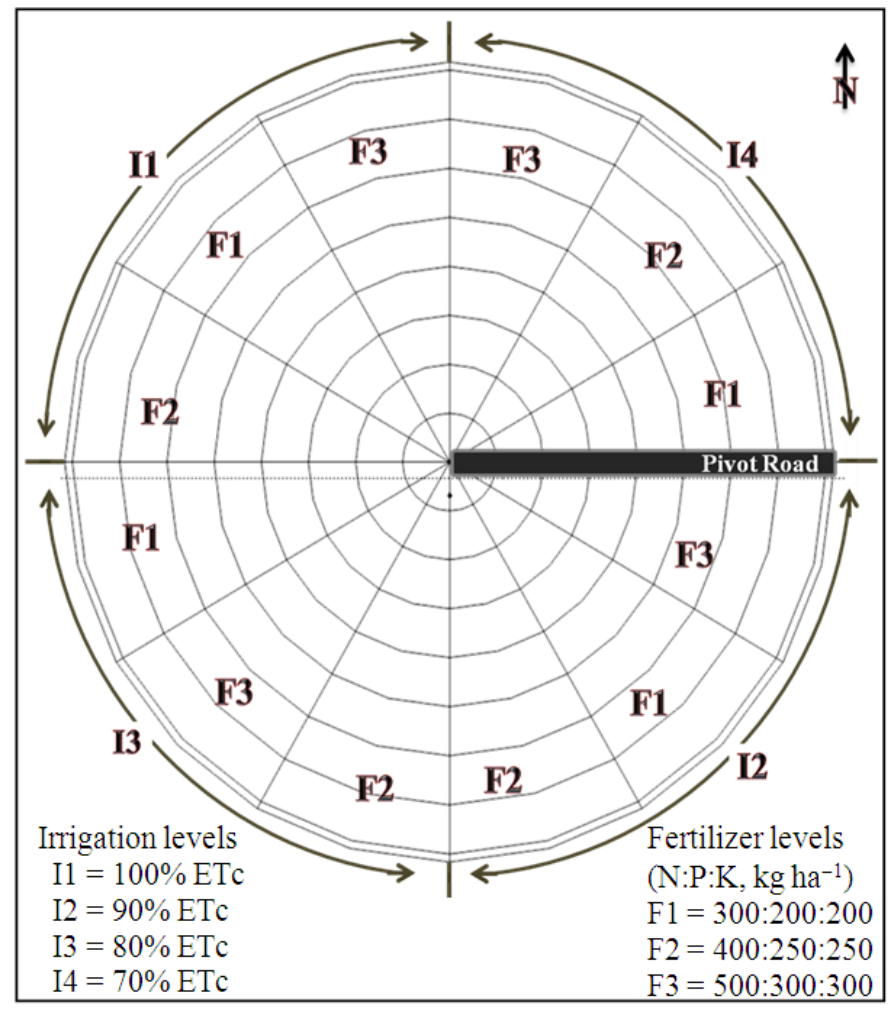

Fig. 2. Layout plan of the experiment

\subsection{Leaf Area Index (LAI) Measurements}

In-situ LAI measurements were made at the same locations and on the same dates of wheat crop sampling for spectral reflectance measurements (i.e., on February 17th and April 5th, 2012) using the Plant. Canopy Analyzer (Model: PCA-2200 of LI-COR Biosciences, USA). At each sampling point, one above canopy and five below canopy readings were recorded to determine a single LAI value.

\subsection{Wheat Crop Yield Data Collection}

Wheat grain yield ( $\mathrm{t} / \mathrm{ha}$ ) data was collected on May 9th, 2012 by harvesting each experimental plot separately using a combine. For each plot, the collected wheat grain was weighed and recorded.

\section{RESULTS}

\subsection{Assessment of the Calculated Spectral Vegetation Indices}

Spectral vegetation indices were calculated from the measured spectral reflectance values of wheat crop samples representing four irrigation levels and three fertilizer levels on two sampling dates (February 17th and April 5th, 2012). To assess the response of the calculated spectral vegetation indices to the irrigation and fertilizer levels applied to wheat crop, the collected data values were subjected to ANOVA statistical analysis. Vegetation indices that showed significant response to irrigation and/or fertilizer treatments are presented in Table 2. It was observed that only 15 out of the 22 investigated spectral indices showed significant response to irrigation levels. Two of those (Plant Senescence Reflectance Index (PSRI) and the Photochemical Reflectance Index (PRI)) were also responsive to fertilizer levels. The results presented in Table 2 revealed that the Middle Infrared-Based Vegetation Index (MIVI) and the Normalized Water Index-2 (NWI-2) were the only two indices that showed significant response to the implemented irrigation levels for both sampling dates. PSRI (for February 17th sampling date) and PRI (for April 5th sampling date) were observed to be significantly sensitive to both irrigation and fertilizer levels. 


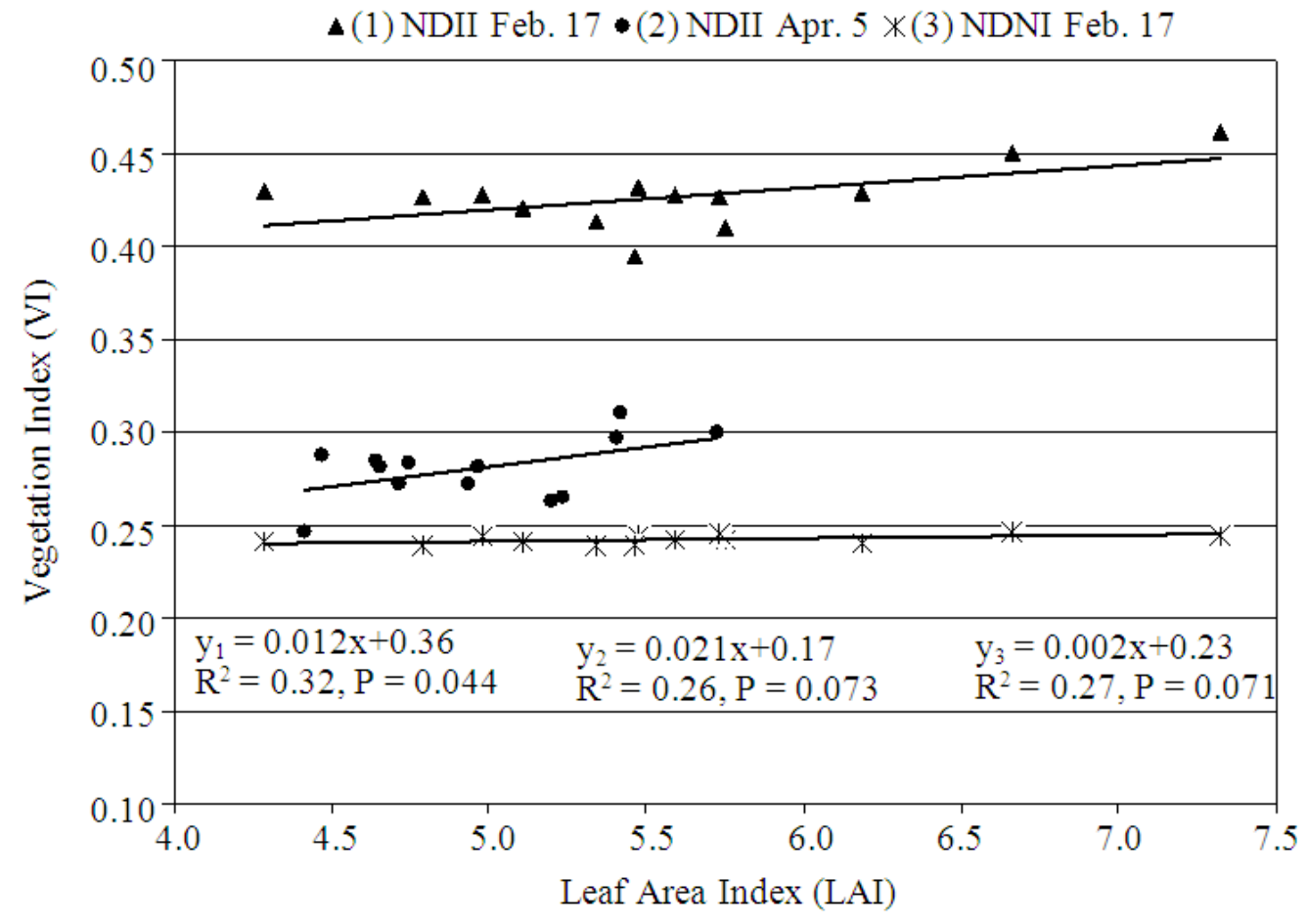

Fig. 3. Relationship of LAI with NDII and NDNI

\subsection{Relationship between Vegetation Indices (VI's) and Leaf Area Index (LAI)}

Leaf area index (LAI) was measured at the same locations and on the same dates of collecting wheat crop samples for spectral reflectance measurements (February 17th and April 5th, 2012). The relationship between the various spectral VI's and LAI is represented by the R-squared values shown in Table 3.

As shown in Table 3, the Normalized Difference Infrared Index (NDII) on both sampling dates (February 17th and April 5th, 2012) and the Normalized Difference Nitrogen Index (NDNI) on February 17th exhibited the strongest relationship with LAI considering the coefficient of correlation (R2) values. The relationship between LAI and both NDII and NDII is illustrated in Fig. 3.

NDII and NDNI exhibited direct linear proportional relationship with LAI Fig. 3. Statistical analysis results showed significant relationship $(\mathrm{P}<0.05)$ only between LAI and NDII for February 17 th measurements (measurements taken at booting growth stage of wheat crop). Therefore, based on the results of the investigated vegetation indices in this study, the NDII can be used as an indicator of wheat crop LAI.

\subsection{Relationship between Spectral Indices and Crop Yield}

The vegetation indices, calculated from wheat crop spectral reflectance measurements taken on February 17th and April, 2012, were correlated with wheat grain yield Table 4 . Results revealed that among the 22 investigated indices, only five (NIR, WBI, NWI1, NWI-3 and NWI-4) showed the most response to wheat grain yield with the highest R2 values (in the range 0.3633 to 0.4894 ). Among those five indices, inverse relationship was observed between wheat grain yield and the Near Infrared band "NIR" (for February 17th measurement) and the Water Band Index "WBI" (for April 5th measurements) Fig. 4. A proportional relationship was observed, for April 5th measurements, between wheat grain yield and the Normalized Water Index-1 (NWI-1), the Normalized Water Index-3 (NWI-3) and the Normalized Water Index-4 (NWI-4) Fig. 5. The Near Infrared Index (NIR), calculated from February 17th measurements (at wheat crop booting growth stage), showed the most significant correlation with wheat grain yield $\left(\mathrm{R}^{2}\right.$ $=0.49, \mathrm{P}=0.011$ ). 
Khalid Ali Al-Gaadi et al. / American Journal of Agricultural and Biological Sciences 9 (2): 138-146, 2014

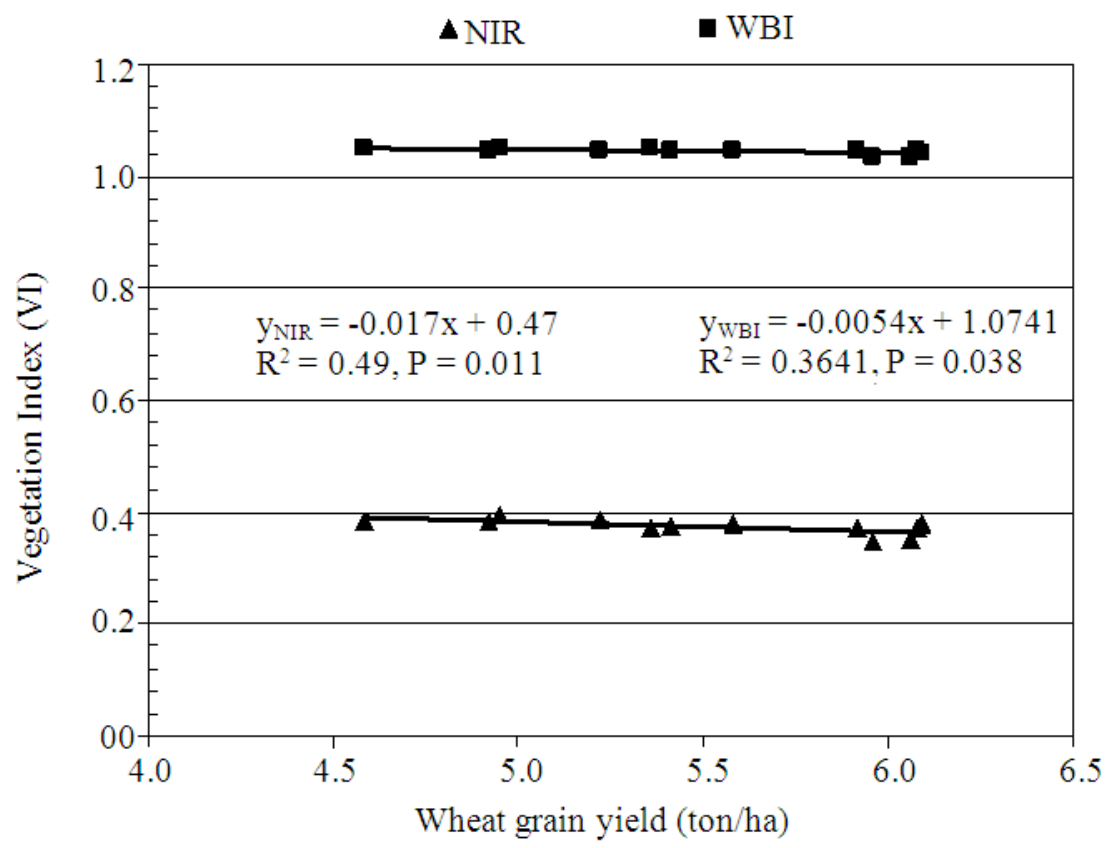

Fig. 4. Relationship of wheat grain yield with WBI and NIR

Wheat grain yield (ton/ha)

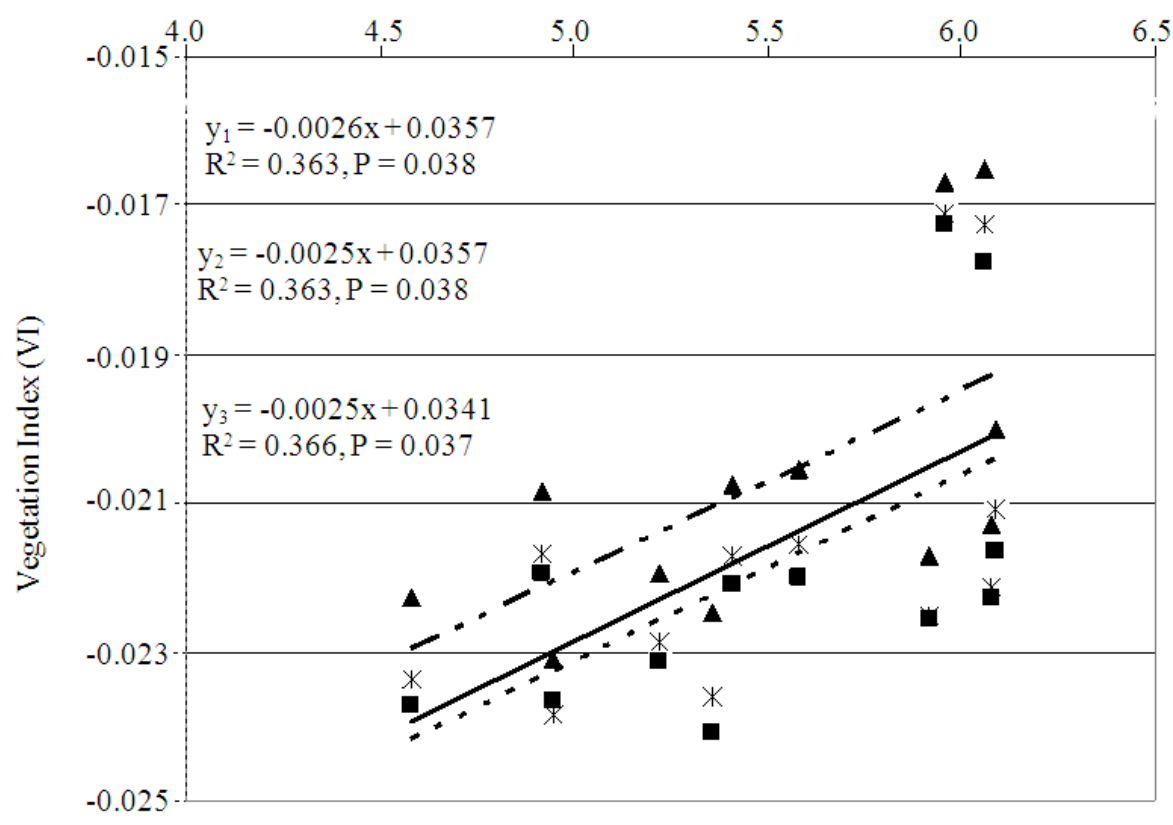

* (1) NWI-1 - (2) NWI-3

Linear ((1) NWI-1) - - - - Linear ((2) NWI-3) - - - Linear ((3) NWI-4)

Fig. 5. Relationship of wheat grain yield with NWI-1, NWI-3 and NWI-4 
Table 2. Response of vegetation indices to irrigation and fertilizer levels

\begin{tabular}{|c|c|c|c|c|}
\hline \multirow{3}{*}{$\begin{array}{l}\text { Spectral } \\
\text { Indices }\end{array}$} & \multicolumn{4}{|l|}{$\operatorname{Pr}>F$} \\
\hline & \multicolumn{2}{|c|}{ Irrigation levels } & \multicolumn{2}{|c|}{ Fertilizer levels } \\
\hline & Feb. 17th & Apr. 5th & Feb. 17th & Apr. 5th \\
\hline$\overline{R E D}$ & $0.0026 * *$ & NS & NS & NS \\
\hline NIR & $0.0170 *$ & NS & NS & NS \\
\hline MIVI & $0.0011 * *$ & $0.0036 * *$ & NS & NS \\
\hline $\mathrm{NDVI}_{705}$ & $0.0250 *$ & NS & NS & NS \\
\hline SIPI & $0.0019 * *$ & NS & NS & NS \\
\hline PSRI & $0.0001 * *$ & NS & $0.0238 *$ & NS \\
\hline NDWI & $0.0085 * *$ & NS & NS & NS \\
\hline NDVI & $0.0047 *$ & NS & NS & NS \\
\hline PRI & NS & $0.0015 * *$ & NS & $0.0261 *$ \\
\hline WBI & NS & $0.0115^{*}$ & NS & NS \\
\hline NWI-1 & NS & $0.0117 *$ & NS & NS \\
\hline NWI-2 & $0.0081 * *$ & $0.0095 * *$ & NS & NS \\
\hline NWI-3 & NS & $0.0132 *$ & NS & NS \\
\hline NWI-4 & NS & $0.0100 *$ & NS & NS \\
\hline REIP & NS & $0.0044 * *$ & NS & NS \\
\hline
\end{tabular}

Table 3. $\mathrm{R}^{2}$ values between VI and LAI

\begin{tabular}{|c|c|c|c|c|c|}
\hline \multirow{2}{*}{$\begin{array}{l}\text { Vegetation } \\
\text { Indices }\end{array}$} & \multicolumn{2}{|l|}{$\mathrm{R}^{2}$} & \multirow{2}{*}{$\begin{array}{l}\text { Vegetation } \\
\text { indices }\end{array}$} & \multicolumn{2}{|l|}{$\mathrm{R}^{2}$} \\
\hline & Feb. 17 & Apr. 5 & & Feb. 17 & Apr. 5 \\
\hline RED & 0.001000 & 0.0391 & NWI-1 & 0.1982 & 0.0352 \\
\hline NIR & 0.024600 & 0.1556 & NWI-2 & 0.1223 & 0.0774 \\
\hline MIVI & 0.000002 & 0.0117 & NWI-3 & 0.1654 & 0.0458 \\
\hline $\mathrm{NDVI}_{705}$ & 0.022900 & 0.0672 & NWI-4 & 0.2391 & 0.0292 \\
\hline SIPI & 0.001900 & 0.0020 & REIP & 0.0094 & 0.0466 \\
\hline PSRI & 0.018600 & 0.0077 & $\mathrm{mSR}_{705}$ & 0.0109 & 0.0629 \\
\hline NDWI & 0.065200 & 0.0025 & $\mathrm{mNDVI}_{705}$ & 0.0161 & 0.1429 \\
\hline MSI & 0.052900 & 0.0685 & VOG3 & 0.0530 & 0.0098 \\
\hline NDVI & 0.003300 & 0.0054 & NDNI & 0.2665 & 0.1004 \\
\hline PRI & 0.022600 & 0.0109 & NDLI & 0.0131 & 0.0860 \\
\hline WBI & 0.198800 & 0.0356 & NDII & 0.3193 & 0.2635 \\
\hline
\end{tabular}

Table 4. Relationship between VI and wheat grain yield

\begin{tabular}{|c|c|c|c|c|c|}
\hline \multirow[b]{2}{*}{$\begin{array}{l}\text { Spectral } \\
\text { Index }\end{array}$} & \multicolumn{2}{|l|}{$\mathrm{R}^{2}$} & \multirow[b]{2}{*}{$\begin{array}{l}\text { Spectral } \\
\text { index }\end{array}$} & \multicolumn{2}{|l|}{$\mathrm{R}^{2}$} \\
\hline & Feb. 17 & Apr. 5 & & Feb. 17 & Apr. 5 \\
\hline RED & 0.3113 & 0.2205 & NWI-1 & 0.0210 & 0.3633 \\
\hline NIR & 0.4894 & 0.0755 & NWI-2 & 0.0079 & 0.2818 \\
\hline MIVI & 0.2480 & 0.2488 & NWI-3 & 0.0162 & 0.3563 \\
\hline $\mathrm{NDVI}_{705}$ & 0.2728 & 0.0642 & NWI-4 & 0.0231 & 0.3655 \\
\hline SIPI & 0.2668 & 0.1189 & REIP & 0.0217 & 0.2283 \\
\hline PSRI & 0.2175 & 0.0460 & $\mathrm{mSR}_{705}$ & 0.0011 & 0.0480 \\
\hline NDWI & 0.2150 & 0.1564 & $\mathrm{mNDVI}_{705}$ & 0.0089 & 0.0204 \\
\hline MSI & 0.2922 & 0.0046 & VOG3 & 0.1002 & 0.1383 \\
\hline NDVI & 0.2771 & 0.1575 & NDNI & 0.0351 & 0.3050 \\
\hline PRI & 0.0873 & 0.3329 & NDLI & 0.1315 & 0.1369 \\
\hline WBI & 0.0214 & 0.3641 & NDII & 0.0843 & 0.1338 \\
\hline
\end{tabular}




\section{DISCUSSION}

Results of the study showed that the best relationship was observed between the NDII and NDNI vegetation indices and wheat crop LAI. The relationship observed could be considered as a relatively weak relationship $\left(\mathrm{R}^{2}\right.$ values were in the range of 0.20 to 0.32 ). Similar results were reported by (Gupta et al., 2006) where lower $\mathrm{R}^{2}$ values of 0.20 to 0.53 were obtained for the relationship between wheat crop LAI and spectral indices, such as Ratio Vegetation Index (RVI), Normalized Difference Vegetation Index (NDVI) and Soil-Adjusted Vegetation Index (SAVI). In contrast, (Haboudane et al., 2004) reported higher $\mathrm{R}^{2}$ values of 0.74 to 0.85 between LAI and VI's, such as Modified Chlorophyll Absorption Ratio Index 2 (MCARI2) and Modified Triangular Vegetation Index (MTVI2).

Statistically significant relationship between LAI and NDII only for February 17th measurements (at wheat crop booting growth stage) was revealed. Similar results were reported by (Zhang et al., 2012), where spectral modeling was thought to be an efficient means for predicting wheat crop LAI at the jointing and booting growth stage and, with less accuracy, at the tillering stage. They also observed that the spectrum measurements taken at the filling stage resulted in the weakest relation between the spectral predicted LAI and the measured LAI. This was attributed to the change in leaves structure at filling stage, where they turned yellow.

Among the 22 investigated indices, five exhibited a significant correlation with wheat grain yield. These five indices included NIR $\left(\mathrm{R}^{2}=0.49, \mathrm{P}=0.011\right)$, WBI $\left(R^{2}=0.36, P=0.038\right)$, NWI-1 $\left(R^{2}=0.36, P=0.038\right)$, NWI-3 $\left(\mathrm{R}^{2}=0.36, \mathrm{P}=0.040\right)$ and NWI-4 $\left(\mathrm{R}^{2}=0.37, \mathrm{P}\right.$ $=0.037)$. These results were in agreement with (Babar et al., 2006) where it was stated that the indices based on NIR (Water Index "WI", Normalized Water Index-1 "NWI-1" and Normalized Water Index-2 "NWI-2") showed the best correlation with wheat grain yield compared to other investigated spectral indices.

Although the most significant relationship between wheat grain yield and spectral indices was recorded for NIR calculated from February 17th measurements at the booting growth stage, the other four indices (WBI, NWI-1, NWI-3 and NWI-4) showing significant correlation with the grain yield were calculated from April 5th measurements at the ripening growth stage. Therefore, based on the results of this study, spectral indices could be significantly used for early wheat yield assessment at the booting growth stage. However, (Royo et al., 2003) reported that the milk-grain stage was the optimum growth stage for wheat yield assessment using spectral indices.

\section{CONCLUSION}

A field study was conducted to determine the vegetation indices that could be used as indicators of wheat crop performance treated with different levels of irrigation water and fertilizer rates. Fifteen out of the 22 investigated spectral indices showed significant response to irrigation levels. However, only two (Plant Senescence Reflectance Index-PSRI and the Photochemical Reflectance Index-PRI) of the fifteen indices also showed significant response to fertilizer levels. The Middle Infrared-Based Vegetation Index (MIVI) and the Normalized Water Index-2 (NWI-2) showed a significant response to the implemented irrigation levels for both sampling dates. The Plant Senescence Reflectance Index (PSRI) and the Photochemical Reflectance Index (PRI) were sensitive to both irrigation and fertilizer levels. Among the investigated spectral indices, only the Normalized Difference Infrared Index (NDII) showed a significant response $(\mathrm{P}<0.05)$ to $\mathrm{LAI}$, hence, it can be used for the prediction of wheat crop LAI. Five indices (NIR, WBI, NWI-1 and NWI-3 and NWI-4) showed significant response to wheat grain yield, however, the NIR was found to produce the most significant correlation with wheat grain yield.

\section{ACKNOWLEDGEMENT}

This research work was carried out under the project (10 SPA 1193-02) funded by the National Plan for Science and Technology (NPST) through King Abdul-Aziz City for Science and Technology (KACST). The assistance provided by the graduate students, namely, Eng. Mohammed Elsiddig Ali Abass, Eng. Ahmed Galal Kaiad and Eng. Ahmed Hassan Zeyada in the field was quite valuable. The unstinted cooperation and support extended by Mr. Jack King and Mr. Alan King in carrying out the field research work are gratefully acknowledged. 


\section{REFERENCES}

Aparicio N., D. Villegas, J. Casadesus, J.L. Arausand and C. Royo, 2000. Canopy Reflectance Indices: A New Tool for Assessing Durum Wheat LAI and Yield. In: Durum Wheat Improvement in the Mediterranean Region: New Challenges, Royo, C., M. Nachit, N.D. Fonzo and J.L. Araus, CIHEAM, Zaragoza, pp: 117-119.

Babar, M.A., M.P. Reynolds, M. van Ginkel and A.R. Klatt et al., 2006. Spectral reflectance indices as a potential indirect selection criteria for Wheat yield under irrigation. J. Crop Sci., 46: 578-588. DOI: 10.2135/cropsci2005.0059

Darvishzadeh R., C. Atzberger and A.K. Skidmore, 2006. Hyperspectral vegetation indices for estimation of leaf area index. Proceedings of the International Society for Photogrammetry and Remote Sensing (ISPRS) Commission VII Symposium 'Remote Sensing: From Pixels to Processes', May 8-11, Enschede.

Duchemin, D., R. Hadria, S. Erraki, G. Boulet and P. Maisongrande et al., 2006. Monitoring wheat phenology and irrigation in Central Morocco: On the use of relationships between evapotranspiration, crops coefficients, leaf area index and remotely-sensed vegetation indices. Agric. Water Manage., 79: 1-27. DOI: 10.1016/j.agwat.2005.02.013

Gupta, R.K., D. Vijayan and T.S. Prasad, 2006. The relationship of hyper-spectral vegetation indices with Leaf Area Index (LAI) over the growth cycle of wheat and chickpea at $3 \mathrm{~nm}$ spectral resolution. Adv. Space Res., 38: 2212-2217. DOI: 10.1016/j.asr.2003.02.091

Gutierrez, M., M.P. Reunolds and A.R. Klatt, 2010. Association of water spectral indices with plant and soil water relations in contrasting wheat genotypes. J. Exp. Bot., 61: 3291-3303. DOI: $10.1093 / \mathrm{jxb} / \mathrm{erq} 156$

Haboudane, D., J.R. Millera, E. Patteyc, P.J. ZarcoTejadadand and I.B. Strachane, 2004. Hyperspectral vegetation indices and novel algorithms for predicting green LAI of crop canopies: Modeling and validation in the context of precision agriculture. Remote Sens. Environ., 90: 337-352. DOI: 10.1016/j.rse.2003.12.013

Haboudane, D., J.R. Miller, N. Tremblay and P. Vigneault, 2007. Indices-based approach for crop chlorophyll content retrieval from hyperspectral data. Proceedings of the IEEE International Geoscience and Remote Sensing Symposium, Jul. 23-28, IEEE Xplore Press, Barcelona, Spain, pp: 3297-3300. DOI: 10.1109/IGARSS.2007.4423549
Hatfield, J.L. and J.H. Prueger, 2010. Value of using different vegetative indices to quantify agricultural crop characteristics at different growth stages under varying management practices. Remote Sens., 2: 562-578. DOI: 10.3390/rs2020562

Herrmann, I., A. Pimstein, A. Karnieli, Y. Cohen and V. Alchanatis et al., 2010. Assessment of leaf area index by the red-edge inflection point from VEN $\mu S$ bands. Proceedings of the 'Hyperspectral Workshop', Mar. 17-19, Frascati, Italy, pp: 1-7.

Lan, Y., H. Zhang, R. Lacey, W.C. Hoffmann and W. $\mathrm{Wu}, 2009$. Development of an integration sensor and instrumentation system for measuring crop conditions. Agric. Eng. Int.: CIGR E-J., 11: 1-16.

Meng, J., B. Wu, Q. Li, X. Du and K. Jia, 2009. Monitoring crop phenology with MERIS data-A case study of winter wheat in North China Plain. Proceedings of the Progress in Electromagnetics Research Symposium, Mar. 23-27, Beijing, China, pp: 1225-1228.

Royo, C., N. Aparicioa, D. Villegasa, J. Casadesusb and P. Monneveuxc et al., 2003. Usefulness of spectral reflectance indices as durum wheat yield predictors under contrasting Mediterranean conditions. Int. J. Remote Sens., 24: 4403-4419. DOI: $10.1080 / 0143116031000150059$

Stellacci, A.M., A. Castrignano, M. Diacono, A. Troccoli and A. Ciccarese et al., 2012. Combined approach based on principal component analysis and canonical discriminant analysis for investigating hyperspectral plant response. Italian J. Agron., 7: 247-253. DOI: 10.4081/ija.2012.e34

Thenkabail, P.S., R.B. Smith and E.D. Pauw, 2002. Evaluation of narrow-band and broad-band vegetation indices for determining optimal hyperspectral wavebands for agricultural crop characterization. Photogrammetric Eng. Remote Sens., 68: 607-621.

Vina, A., A.A. Gitelson, A.L. Nguy-Robertson and Y. Peng, 2011. Comparison of different vegetation indices for the remote assessment of green leaf area index of crops. Remote Sens. Environ., 115: 34683478. DOI: 10.1016/j.rse.2011.08.010

Zhang, R., J. Ba, Y. Ma, S. Wang and J. Zhang et al., 2012. A comparative study on wheat leaf area index by different measurement methods. Proceedings of the 1st International Conference on Agro-Geoinformatics, Aug. 2-4, IEEE Xplore Press, Shanghai, pp: 1-5. DOI: 10.1109/AgroGeoinformatics.2012.6311671 